\title{
Atuação da enfermagem frente à violência sexual contra crianças e adolescentes
}

\author{
Nursing actions face to sexual violence against children and adolescents \\ Actuación de la enfermería frente a la violencia sexual contra niños y adolescentes
}

\section{Lygia Maria Pereira da Silva', Maria das Graças de Carvalho Ferriani", Marta Angélica lossi Silva" \\ ' Universidade de Pernambuco, Faculdade de Enfermagem Nossa Senhora das Graças. Recife-PE, Brasil. Universidade de São Paulo, Escola de Enfermagem de Ribeirão Preto, Programa Interunidades de Doutoramento em Enfermagem. (Doutoranda) Ribeirão Preto-SP, Brasil. \\ "Universidade de São Paulo, Escola de Enfermagem de Ribeirão Preto, \\ Programa Interunidades de Doutoramento em Enfermagem. Ribeirão Preto-SP, Brasil.}

Submissão: 14-08-2010 Aprovação: 13-10-2011

\section{RESUMO}

Este estudo objetivou refletir sobre a violência sexual contra crianças e adolescentes, focalizando a atuação do enfermeiro à luz da sua prática profissional e da legislação brasileira. Trata-se de estudo bibliográfico em que foram analisadas 31 publicações, abrangendo os anos de 2005 a 2008. Para análise dos dados utilizou-se a análise de conteúdo, modalidade temática, evidenciando três núcleos temáticos: a atenção à saúde da criança e do adolescente, a notificação e a qualificação profissional. $\mathrm{O}$ enfermeiro deve estar apto a cuidar da criança e do adolescente com base nas leis que os protegem, sendo imperativo o envolvimento dos serviços de saúde, das entidades de classe e das universidades.

Descritores: Violência sexual; Criança; Adolescente; Papel do profissional de enfermagem.

\section{ABSTRACT}

The objective of this work was to think over the sexual violence against children and adolescents, focusing on the nurses` performance regarding their professional practice and Brazilian legislation. This is a bibliographical study in which 31 publications covering the period from 2005 until 2008 were researched. Through content analysis, thematic modality, the knowledge characterization was obtained in three cores: attention towards children and adolescents' health, notification and professional qualifications. The nurse must be able to care of children and adolescents based on the laws that protect them, being an imperative for that the involvement of health services, class entities and universities.

Key words: Sexual Violence; Child; Adolescent; Role of Nursing Professional.

\section{RESUMEN}

Este estudio tuvo como objetivo reflexionar sobre la violencia sexual contra niños y adolescentes, enfatizando la actuación del enfermero con base en su práctica profesional y en la legislación brasileña. Se trata de un estudio bibliográfico en el que se analizaron 31 publicaciones, abarcando los años del 2005 al 2008. Para análisis de los datos se utilizó el análisis del contenido, modalidad temática, evidenciando tres núcleos temáticos: atención a la salud del niño y del adolescente, la notificación y la cualificación profesional. El enfermero debe estar apto para cuidar de los niños y de los adolescentes basándose en las leyes que los protegen, siendo fundamental la participación de los servicios de salud, de las entidades de clase y de las universidades. Palabras clave: Violencia Sexual; Niño; Adolescente; Papel del Profesional de Enfermería. 


\section{INTRODUÇÃO}

Vários problemas dificultam o enfrentamento da violência sexual contra crianças e adolescentes, como o posicionamento dos profissionais da saúde, muitas vezes permeado pelo medo e pelo desconhecimento da real magnitude e impacto desse fenômeno na sociedade, nas famílias e na vida de crianças e adolescentes. Isto ainda coloca em pauta a necessidade de se apropriar de um referencial teórico-analítico, capaz de permitir a compreensão do problema levando-se em consideração sua complexidade e suas diferentes formas de manifestação.

Nos Estados Unidos da América, mais de uma em cada oito crianças e adolescentes entre dois e dezessete anos sofreram alguma forma de violência ${ }^{(1)}$.Estudos brasileiros sobre a violência sexual contra crianças e adolescentes revelam que todas as faixas etárias são vitimizadas, e as vítimas, em sua maioria, são crianças entre nove e 12 anos de idade, do sexo feminino, e os agressores são pessoas conhecidas, com maior frequência pais e padrastos, sendo significativa a incidência de tios, irmãos mais velhos etc. ${ }^{(2-5)}$. Pesquisa realizada em Feira de Santana, Bahia, entre 2003-2004 revelou que de 1.293 casos de violência contra crianças e adolescentes, $78 \%$ das ocorrências se passaram no domicílio( ${ }^{(6)}$.

A Organização Mundial de Saúde (OMS) define o abuso sexual de crianças como "o envolvimento de uma criança em atividade sexual que ele ou ela não compreende totalmente, não tem capacidade para dar seu consentimento informado ou para o qual a criança, por seu desenvolvimento, não está preparada e não pode consentir ou que viola as leis ou tabus sociais"(7). Várias são as consequências da violência sexual contra crianças e adolescentes, as quais se apresentam em diversos níveis de gravidade. Os principais danos físicos são lesões genitais e anais, como lacerações, fissuras, sangramentos, doenças sexualmente transmissíveis, gravidez, entre outros. Os danos psicossociais são distintos, como, por exemplo, distúrbios de sono e alimentação, baixo rendimento escolar, fugas de casa, depressão, uso abusivo de substâncias psicoativas, delinquência, prostituição e risco de revitimização ao longo da vida ${ }^{(4,7)}$.

O recorte do nosso estudo é o da violência sexual contra crianças e adolescentes. $\mathrm{O}$ interesse pelo estudo do tema se deve à percepção de problemas apontados pelos enfermeiros que, como outros profissionais de saúde, apresentam dificuldades ao se depararem com crianças e adolescentes vitimizadas e se veem em meio a conflitos relacionados a normas culturais, éticas e legais, o que requer o conhecimento da legislação para uma assistência efetiva às necessidades das vítimas.

Além disso, entende-se que a enfermagem, enquanto uma prática social, deve se apropriar de maior conhecimento sobre a temática em estudo e estabelecer no seu processo de trabaIho a dimensão cuidadora na perspectiva do cuidado individual e coletivo, por meio da sua prática clínica, educacional e administrativa/gerencial, respondendo a uma dimensão plural de necessidades e demandas. Desta forma, buscando responder aos desafios de tirar a violência sexual contra crianças e adolescentes da clandestinidade; compreender melhor o processo de produção desse fenômeno e formar profissionais competentes e socialmente comprometidos no seu enfrentamento. Neste sentido, o presente trabalho objetivou refletir sobre a violência sexual contra crianças e adolescentes, focalizando a atuação do enfermeiro na sua prática à luz da legislação brasileira sobre o tema.

\section{METODOLOGIA}

O estudo é de cunho bibliográfico, e o levantamento de dados foi realizado nas bases de periódicos da BVS (Biblioteca Virtual de Saúde) acessando-se o LILACS (Sistema Latino Americano e do Caribe de Informações em Ciências da Saúde) e o SCIELO (Scientific Eletronic Library Online), utilizando, como descritores, "criança", "adolescente", "enfermagem", "violência sexual", "maus-tratos sexuais infantis" e "legislação".

Utilizaram-se os seguintes critérios para a seleção dos trabalhos: possuir resumo disponível nas bases de dados; período de publicação de 2005 a 2008, considerando que a publicação das normas técnicas vigentes do Ministério da Saúde (MS) para o atendimento a vítimas de violência sexual se deu no ano de 2005; tratar da temática em estudo, ou seja, a violência sexual contra crianças e adolescentes e a atuação do enfermeiro à luz da legislação brasileira sobre o tema.

Foram excluídos os trabalhos não relevantes, as repetições, artigos que não apresentavam resumo, artigos escritos em outros idiomas que não o português, uma vez que o enfoque desta investigação era na legislação brasileira ou com óbvias limitações metodológicas. Para a análise dos dados, se procurou interpretar os sentidos das ideias centrais dos artigos a partir da técnica de análise de conteúdo, modalidade temáti$\mathrm{Ca}^{(8)}$. Após seleção dos textos, procedeu-se à leitura flutuante e organizou-se o corpus de análise, conforme os objetivos do estudo. Após leituras exaustivas, foram identificadas as unidades de registro que foram agrupadas em núcleos temáticos que emergiram das publicações.

\section{RESULTADOS}

\section{Características gerais da produção analisada}

Inicialmente foram coletadas 77 referências, nacionais e internacionais, em sua maioria de periódicos. Após a implementação dos critérios de inclusão e exclusão, foram selecionados por sua pertinência e especificidade 31 trabalhos: 16 artigos nacionais, 02 dissertações, 03 teses, e 10 documentos oficiais, constituídos por leis, portarias e normas técnicas brasileiras. A pesquisa constou de trabalhos realizados por enfermeiros e por outros profissionais que, em sua maioria, contemplam uma abordagem multiprofissional do objeto em estudo. Variaram em frequência, como estudos de relato de experiência (02), reflexão teórica (04), estudos epidemiológicos (05), revisões bibliográficas (03), estudos de caso (07), leis, portarias, normas técnicas federais (10). Entre os artigos, dissertações e teses, 13 são de autoria de enfermeiros, 02, de enfermeiros com outros profissionais, 04 , de autoria somente de outros profissionais, e em 02 textos não foi possível identificar a categoria a qual pertencem os autores. As leis, portarias e normas 
técnicas federais dispõem sobre a legislação do tema e são originadas dos Ministérios da Saúde e Justiça e da Presidência da República (10). A maioria (15) aborda a violência sexual juntamente com as outras formas de violência contra crianças e adolescentes, enquanto 09 abordam especificamente a violência sexual, desses, 02 abordam o atendimento à mulher e a assistência à criança como esporádica nos serviços. Textos que abordam a violência contra a mulher foram selecionados 06, por abarcarem os diferentes grupos etários e por não haver norma técnica equivalente para crianças e adolescentes.

A análise da produção estudada possibilitou a constituição de três núcleos temáticos: a atenção à saúde da criança e do adolescente vitimizados sexualmente, a notificação e a qualificação profissional. O núcleo temático atenção à saúde de crianças e adolescentes vitimizados apresenta três subtemas, a saber: o diagnóstico, o tratamento dos agravos resultantes da violência e as ações educativas.

\section{Atenção à saúde da criança e adolescente vitimizados sexualmente}

A atenção à saúde de crianças e adolescentes vitimizados sexualmente é abordada em várias produções científicas como uma ação multiprofissional e um desafio para o setor da saúde, tendo em vista a necessidade de mudança de paradigma para o enfrentamento do problema ${ }^{(5,9-11)}$. A violência sexual é abordada como questão ética e jurídica que diz respeito ao campo dos direitos humanos ${ }^{(11-14)}$, e a atuação da enfermagem é percebida como ampla e complexa, abrangendo a participação no diagnóstico, no tratamento dos agravos resultantes da violência, nas ações educativas (orientação, encaminhamento etc.) e na notificação(9-11).

\section{O diagnóstico da violência sexual contra crianças e adolescentes}

O diagnóstico é enfatizado como o primeiro passo na atenção à saúde da vítima, sendo evidenciada a importância da anamnese e do exame físico como primordial para a identificação de sinais físicos e comportamentais ${ }^{(9-12,14-17)}$.Ponderando que todos os sinais devem ser considerados dentro de um contexto, alguns autores percebem como indispensável a atuação em equipe e a busca de evidências encontradas por outros profissionais que também atendem a criança $\mathrm{a}^{(7,11,15,18)}$.

O MS e a OMS recomendam que, para auxiliar no diagnóstico, seja colhido material para exames laboratoriais e forenses. Deve ser colhido material (swab) das cavidades oral, vaginal e retal, como também fazer coleta para culturas, pesquisa sorológica para DST/HIV, hepatites, sífilis, tipagem sanguínea, fosfatases e pesquisa de DNA. As amostras para pesquisa de sêmen, sangue e células epiteliais devem ser acondicionadas em papel-filtro esterilizado, guardadas em envelope de papel, pois o plástico retém umidade e facilita a proliferação de bactérias que destroem células coletadas e DNA. Depois de seco, arquivar o material, de preferência em ambiente climati$z^{2}{ }^{(7,19)}$, e o mais breve possível encaminhar sob ofício para o Instituto Médico Legal (IML) ${ }^{(11)}$.Quando não forem tomadas medidas para anticoncepção de emergência, realizar exame sanguíneo e ultrassonografia, para diagnosticar gravidez ${ }^{(7,20)}$.

Vários autores se referem à importância do conhecimento dos profissionais de saúde a respeito das políticas de enfrentamento do problema e das normas técnicas para o diagnóstico adequado $^{(4-5,9,11,14-16,21)}$, mas poucos mencionam recomendações contidas nas leis, no tocante aos métodos utilizados para diagnóstico no setor saúde.Contudo, alguns estudos abordam a utilização de exames laboratoriais e radiológicos para diagnóstico da violência sexual ${ }^{(11,14)}$, assim como a investigação para detecção de doenças sexualmente transmissíveis e HIV/AIDS ${ }^{(4,11)}$.

\section{O tratamento dos agravos resultantes da violência}

Quanto ao tratamento dos agravos resultantes da violência, a exemplo do que foi verificado no item diagnóstico, poucos autores apresentam em seus textos alusão às recomendações contidas nas leis. O MS recomenda aos profissionais o conhecimento sobre a indicação e efeitos adversos de procedimentos para prestar cuidados às vítimas e suas famílias, devendo estar qualificados para a profilaxia de DST, hepatites virais e HIV, tétano (quando a lesão teve contato com terra) e gravidez, medidas que devem ser tomadas até as primeiras 72 horas do evento, como a anticoncepção de emergência e a quimioprofilaxia ${ }^{(19-20,23)}$.Tais recomendações foram encontradas em duas produções, as quais adotam uma abordagem interdisciplinar do problema ${ }^{(11,18)}$.

Para se estabelecer, quando necessário, a terapia antirretroviral às vítimas, deve-se buscar o agressor para realização da sorologia anti HIV sempre que possível. A enfermeira faz a busca e solicita a autorização formal do agressor para a coleta do exame. Tal procedimento tem por finalidade a manutenção ou suspensão da administração dos antirretrovirais ${ }^{(22)}$.

Quando não se adotam as profilaxias específicas, pode ocorrer a gravidez, causa de transtornos adicionais à saúde física e psíquica da vítima ${ }^{(11,19-20)}$. Concordando com a recomendação do $\mathrm{MS}^{(17)}$, duas publicações consideram que a vítima e sua família devem receber esclarecimentos, para que possam escolher entre levar a gravidez a termo e criar a criança, ou dar o bebê para adoção, ou ainda, optar pelo abortamento $^{(11,18)}$. Nas duas primeiras possibilidades no acompanhamento pré-natal, parto e puerpério, considera-se além do aspecto biológico desses processos, o aspecto psicossocial, devendo a equipe atentar para o surgimento de transtornos psíquicos, para os quais existe maior risco ${ }^{(18,23-24)}$.

A interrupção da gravidez decorrente de estupro é permitida por lei, conforme o Art. 128, inciso II do Código Penal(25). $\mathrm{O}$ MS, observando o disposto no referido artigo, regula a interrupção de gravidez prevista em lei na Portaria GM/MS No $1.508 / 2005$ e anexos, não estando o procedimento condicionado à decisão judicial ou apresentação de boletim de ocorrência policial, mas à assinatura de termo de responsabilidade pelos responsáveis ${ }^{(19,26)}$.

O dilema ético vivenciado pelos profissionais quando no cumprimento dessa lei é abordado como uma questão dificultadora à atuação do profissional ${ }^{(4,11,14-18)}$. O mesmo tem direito de se recusar a participar do abortamento, alegando objeção de consciência. No entanto, essa recusa não deve prejudicar 
a realização do procedimento, pois o serviço de saúde deve providenciar a realização do abortamento em tempo hábil, por meio do atendimento de outro profissional ${ }^{(19,26)}$.

Estudos apontam a elaboração de protocolo e capacitação como medida para melhorar a atuação profissional, efetivando a garantia do direito às vítimas ${ }^{(12,16)}$. Também se considera importante a discussão dos dilemas éticos, para reflexão sobre as suas práticas e aperfeiçoamento da sua atuação ${ }^{(9,11,27)}$.

\section{As ações educativas}

Ações educativas junto às famílias são mencionadas, caracterizando as formas de prevenção primária, secundária $^{(9,11,14-18,28-29)}$ e terciáriaa ${ }^{(10-11,29)}$. Tais ações são descritas na Política Nacional de Redução da Morbimortalidade por Acidentes e Violências do $\mathrm{MS}^{(30)}$.

As ações para abordagem da família apresentam-se na forma de orientação aos pais sobre o direito de a criança crescer sem violência e os efeitos da mesma para a saúde da vítima, buscando adesão ao tratamento dos agravos resultantes da violência e esclarecendo sobre os deveres dos adultos responsáveis em relação à segurança e ao bem-estar das crianças. Um artigo descreve ações educativas dirigidas à família em situação de violência sexual intrafamiliar, considerando todos os membros como alvo dos cuidados do (a) enfermeiro (a) ${ }^{(28)}$.

São recomendadas ações a serem realizadas nos serviços de atenção primária, secundária e terciária, tendo a consulta de enfermagem como importante instrumento no atendimento $^{(15,18,28-29,31)}$. A proteção à vítima é efetivada com ações realizadas especialmente junto às mães, já que, segundo os autores, em muitos casos, a violência ocorre por longo tempo sem o conhecimento da mesma ${ }^{(15,29)}$.

\section{A notificação}

A obrigatoriedade da notificação é justificada não somente pelos danos causados à saúde da vítima e pelo aspecto criminal da violência, mas, sobretudo por se constituir um instrumento de proteção e defesa dos direitos de crianças e adolescentes vitimizados. A notificação ainda subsidia a elaboração de políticas públicas e a adequação de novas propostas de atenção integral, na medida em que revela a magnitude do fenômeno da violência sexual. ${ }^{(2,11,13,15,31)}$. Sobre tal aspecto, o desconhecimento do enfermeiro a respeito da legislação revela-se importante causa das dificuldades, na abordagem dos casos.

O Código Penal Brasileiro, Decreto-Lei no 2.848,de 07 de dezembro de 1940, recentemente reformado,é o documento que define no Título VI, Capítulo I, dos crimes contra a dignidade sexual, no seu Art. 213 a violência sexual como crime. A lei limita a idade de consentimento para relações sexuais para 18 anos, considerando que antes dessa idade a pessoa não pode consentir, pois não tem maturidade para compreender e assumir as consequências de uma relação sexual. O mesmo documento, no Capítulo II, dos crimes contra vulneráveis no Art. 217-A, qualifica o crime se a vítima não é maior de 14 anos, é portadora de enfermidade ou deficiência mental, não tendo discernimento para a prática do ato ou não pode oferecer resistência ${ }^{(25)}$.
A notificação da violência sexual contra crianças e adolescentes recebe grande ênfase por ser, segundo os autores, o primeiro passo dado no setor da saúde para a proteção à vítima e responsabilização do agressor ${ }^{(5,11-16,21)}$. O Estatuto da Criança e do Adolescente (ECA) esclarece que, por meio da notificação do fato, inicia-se um processo que visa a interromper comportamentos violentos contra crianças e adolescentes, pois são desencadeadas ações de vários setores ${ }^{(8)}$.

No setor da saúde, a notificação tornou-se obrigatória para os profissionais por meio da lei federal, a Portaria $n^{\circ}$ 1.968/2001 MS. Esta lei orienta que a comunicação dos casos também deve ser encaminhada para a vigilância epidemiológica, pois os números obtidos auxiliam no planejamento de políticas públicas e permitem o desenvolvimento de pesquisas ${ }^{(33)}$.

O Código de Ética de Enfermagem considera dever do profissional a proteção de seus clientes em situações graves, e esclarece que se configura como justa causa a comunicação das situações de violência às autoridades competentes ${ }^{(34)}$. O compartilhamento de informações com outros profissionais da equipe visando à proteção da criança é valorizado e considerado um dever do (a) enfermeiro (a) ${ }^{(11)}$.

Alguns profissionais temem o envolvimento em casos de violência, por medo de represália e de demandas judiciais, como a convocação para prestar depoimento ${ }^{(5,11,15,17)}$. Porém, a resistência diante dos riscos inerentes à intervenção deve ser superada com estratégias que considerem a complexidade do problema ${ }^{(17)}$, devendo o serviço esclarecer os profissionais e criar condições para que atuem em segurança ${ }^{(5,11,15)}$. O compartilhamento da responsabilidade entre o profissional que realiza o atendimento e o gestor é apontado como meio de proporcionar maior proteção ao notificante ${ }^{(17)}$. Ressalta-se que o ato de notificar não encerra a atuação do enfermeiro na atenção às vítimas que continuarão precisando de acompanhamento ${ }^{(5,11,15-17)}$.

\section{A qualificação profissional}

A qualificação do enfermeiro foi mencionada como uma urgência para o efetivo enfrentamento da violência sexual e, por outro lado, a falta dessa qualificação é apontada como uma das causas do descompasso entre a atuação do profissional e as necessidades das vítimas ${ }^{(5,10-11,15-16)}$. As entidades de classe, as instituições de saúde e de ensino superior são apontadas como responsáveis pelo suporte e pela qualificação dos enfermeiros. O suporte referido abrange desde o estímulo às ações, como campanhas e eventos sobre o tema, até o apoio jurídico ${ }^{(15)}$. As instituições de saúde também são assinaladas como responsáveis pela qualificação do enfermeiro, sendo a educação permanente considerada imprescindível, devendo ser realizada em parceria com as universidades, o que permitiria uma troca de experiências entre os profissionais da assistência e os docentes ${ }^{(5,9-11,31)}$.

A importância do papel das universidades no ensino do tema violência está tanto na graduação quanto nos vários outros níveis ${ }^{(5,11,15-16,31)}$. As Diretrizes Curriculares Nacionais que dispõem sobre os cursos de graduação em Enfermagem, Medicina e Nutrição têm como objetivo a construção de um perfil acadêmico e profissional com competências, habilidades 
e conteúdos que contemplem perspectivas e abordagens contemporâneas $^{(35)}$. Tal perfil se faz necessário para o enfrentamento da violência sexual contra crianças e adolescentes, problema tão complexo e de grande impacto na saúde.

\section{CONSIDERAÇÕES FINAIS}

O presente estudo constatou que a produção científica no tema é escassa, predominando as pesquisas que tratam da dimensão e magnitude do problema, tendo em vista a atuação do enfermeiro e dos gestores, priorizando o cuidado à vítima e sua família. Percebeu-se a carência de normas técnicas específicas do setor da saúde para o atendimento às crianças e aos adolescentes em situação de violência sexual, em detrimento de uma atenção qualificada e contextualizada a este grupo etário.

O estudo confirma o pressuposto de que o (a) enfermeiro (a) e outros profissionais de saúde apresentam dificuldades ao se depararem com crianças e adolescentes vitimizados e se veem em meio a conflitos relacionados a normas culturais, éticas e legais, o que requer conhecimento da legislação para uma assistência efetiva às necessidades das vítimas e das suas famílias.

Diante da complexidade e do impacto da violência sexual na saúde das crianças e adolescentes, o presente estudo vem contribuir para potencializar o envolvimento do enfermeiro na abordagem e na atenção baseadas no paradigma da proteção integral. Evidencia-se a necessidade de incluir esse tema na formação do enfermeiro, no sentido de instrumentalizá-lo para a sua atuação junto a crianças e adolescentes em situação de violência sexual. Da mesma forma, revela-se imprescindível o envolvimento dos serviços de saúde, dos órgãos de classe e das instituições de ensino superior na qualificação dos profissionais de enfermagem para uma atuação comprometida e competente.

\section{REFERÊNCIAS}

1. Finkelhor D, Ormrod R, Turner H, Hamby SL. The victimization of children and youth: a comprehensive, national survey. Child Maltreat 2005 Feb;10:5-25.

2. Maranhão VF. Prevalência de maus-tratos em crianças e adolescentes, ocorridos na cidade do Recife. [dissertação]. Recife (PE): Universidade de Pernambuco; Programa de Pós-graduação em Odontologia; 2005.

3. Roque EMST. Estudo das famílias de crianças e adolescentes vítimas de violência que tiveram intervenção da justiça em Comarca de vara única - Estado de São Paulo - Brasil. [tese]. Ribeirão Preto(SP): Universidade de São Paulo; Programa de Pós-graduação em Enfermagem; 2006.

4. Aded NLO, Dalcin, BLGS, Cavalcanti MT. Estudo da incidência de abuso sexual contra crianças no Rio de Janeiro. Cad. Saúde Pública 2007 ago;23(8):1971-75.

5. Silva MAI, Ferriani MGC. Violência doméstica: do visível ao invisível. [periódico online] Rev. Latino-Am Enfermagem. 2007 mar/abr [citado em 20 jan 2009];15(2). Disponível em: http://www.scielo.br/scielo.php?script =sci arttext\&pid $=$ S0104-11692007000200013\&Ing $=$ pt\&nrm $=\mathrm{iso} \& \operatorname{lng}=\mathrm{pt}$

6. Costa COM, Carvalho RC, Bárbara JFRS, Santos CAST, Gomes WA, Sousa HL. O perfil da violência contra crianças e adolescentes, segundo registros de Conselhos Tutelares: vítimas, agressores e manifestações de violência. Ciênc. Saúde Coletiva. 2007 set/out;12(5):1129-41.

7. World Health Organization (WHO). Guidelines for medico-legal care for victims of sexual violence. Geneve; 2003.

8. Minayo MCS. O desafio do conhecimento: pesquisa qualitativa em saúde. São Paulo(SP): Hucitec; 2007.

9. Cunha JM, Assis SG, Pacheco STA. A enfermagem e a atenção à criança vítima de violência familiar. Rev. Bras. Enferm. 2005 jul/ago;58(4):462-5.

10. Algeri S, Souza LM. Violência intrafamiliar contra a criança: uma análise crítico-reflexiva para a equipe de enfermagem. Online Braz J Nurs. [Periódico online]2005[citado em 20 jan 2009];4(3). Disponível em: http://www.uff.br/ nepae/objn302pennaetal.htm

11. Silva LMP. Atendimento a crianças e adolescentes em situação de abusosexual: o discurso dos profissionais da saúde [dissertação].Fortaleza(CE): Universidade Federal do Ceará; Programa de Pós-graduação em Enfermagem; 2006.

12. Zottis GAH, Algeri S, Portella VCC. Violência intrafamiliar contra a criança e as atribuições do profissional de enfermagem. Fam. Saúde Desenv. 2006 maio/ago;8(2):146-53.

13. Saliba O, Garbin CAS, Garbin AJI, Dossi AP. Responsabilidade do profissional de saúde sobre a notificação de casos de violência doméstica. Rev. Saúde Pública. 2007 jun;41(3):472-7.

14. Ciuffo LL, Rodrigues BMRD, Cunha JM. The nurse facing childhood sexual abuse diagnosis. Online Braz. J. Nurs. [Periódico online].2008[citado em 20 jan 2009];7(1). Disponível em: http://www.uff.br/nepae/objn302pennaetal. htm

15. Cunha JM. A atenção de enfermagem à criança vítima de violência familiar [tese]. Rio de Janeiro (RJ): Instituto Fernandes Figueira; Programa de Pós-graduação em Saúde da criança e da Mulher; 2007.

16. Algeri S, Almoarqueg SR, Borges RSS, Quaglia MC, Marques MF. Violência intrafamiliar contra a criança no contexto hospitalar e as possibilidades de atuação do enfermeiro. Rev. HCPA. 2007;27(2).

17. Santos NC. Práticas sanitárias frente à violência intrafamiliar no âmbito do PSF - um estudo de caso [tese] Rio de Janeiro(RJ): Escola Nacional de Saúde Pública Sérgio Arouca; Programa de Pós-graduação em Ciências na área de Saúde Pública; 2005.

18. Higa R, Mondaca ADCA, R MJ, Lopes MHBM. 
Atendimento à mulher vítima de violência sexual: protocolo de assistência de enfermagem. Rev. Esc. Enferm. USP. 2008 jun;42(2):377-82.

19. Ministério da Saúde (BR). Secretaria de Atenção à Saúde. Departamento de Ações Programáticas e Estratégicas. Área Técnica Saúde da Mulher. Aspectos jurídicos do atendimento às vítimas de violência sexual: perguntas e respostas para profissionais de saúde. Brasília (DF): MS; 2005.

20. Ministério da Saúde (BR). Secretaria de Atenção à Saúde. Departamento de Ações Programáticas e Estratégicas. Área Técnica Saúde da Mulher. Anticoncepção de emergência. Brasília (DF): MS; 2005.

21. Ricas J, Donoso MTV, Gresta MLM. Maus-tratos na infância: reflexões. REME - Rev. Min. Enf. 2006 jul./ set;10(3):306-310.

22. Campos MAMR, Schor N. Violência sexual como questão de saúde pública: importância da busca ao agressor. Saúde Soc. 2008 jul/set;17(3):190-200.

23. Ministério da Saúde (BR). Secretaria de Atenção à Saúde. Departamento de Ações Programáticas e Estratégicas. Área Técnica Saúde da Mulher. Prevenção e tratamento dos agravos resultantes da violência sexual contra mulheres e adolescentes. Brasília (DF): MS; 2005.

24. Ministério da Saúde (BR). Secretaria de Atenção à Saúde. Departamento de Ações Programáticas e Estratégicas. Área Técnica Saúde da Mulher. Atenção integral para mulheres em situação de violência doméstica e sexual. Brasília (DF): MS; 2006.

25. Pinto ALT, Windt MCV, Céspedes L. VadeMecum. $9^{\text {a }}$ ed São Paulo: Saraiva; 2010.

26. Ministério da Saúde (BR). Secretaria de Atenção à Saúde. Departamento de Ações Programáticas e Estratégicas. Área Técnica Saúde da Mulher. Atenção humanizada ao abortamento. Brasília: MS; 2005.
27. Aded NLO, Dalcin BLGS, Moraes TMM, Cavalcanti M T. Abuso sexual em crianças e adolescentes: revisão de 100 anos de literatura. Rev. Psiq. Clín. 2006;33(4):204-13.

28. Silva LMP, Galvão MTG, Araújo TL, Cardoso MVLML. Cuidado à família de crianças em situação de abuso sexual baseado na teoria humanística. Online Braz. J. Nurs. [Periódico online] 2007[citado em 20 jan 2009];6(1). Disponível em: http://www.uff.br/nepae/objn302pennaetal.htm

29. Monteiro CFS, Teles DCBS, Castro KL, Vasconcelos NSV, Magalhães RLB, Deus MCBR. Violência sexual contra crianças no meio intrafamiliar atendidos no SAMVVIS, Teresina, PI. Rev Bras Enferm. 2008 jul/ago;61(4):459-63.

30. Ministério da Saúde (BR). Portaria MS/GM n 737, de 16 de maio de 2001: política nacional de redução da morbimortalidade por acidentes e violências. Diário Oficial [da] República Federativa do Brasil 2001; sect. 1E; 96.

31. Gomes ILV, Caetano R, Jorge MSB. A criança e seus direitos na família e na sociedade: uma cartografia das leis e resoluções. Rev Bras Enferm. 2008 jan/fev;61(1):61-5.

32. Recife(PE) Centro de Defesa da Criança e do Adolescente (CEDECA). Estatuto da Criança e Adolescente: Lei 8.069.; 2008.

33. Ministério da Saúde (BR). Secretaria de Assistência à Saúde. Notificação de maus-tratos contra crianças e adolescentes pelos profissionais de saúde: um passo a mais na cidadania em saúde. Brasília (DF): MS; 2002. (Série A n 167)

34. Conselho Federal de Enfermagem. Código de ética de enfermagem. [online] Brasília (DF); 2008. [citado em 8 nov 2008]. Disponível em: http://www.portalcofen.gov.br

35. Ministério da Educação (BR). Conselho Nacional de Educação. Parecer CNE/CES n ${ }^{\circ} 1.133$, de 7 de agosto de 2001: estabelece as Diretrizes Curriculares Nacionais dos Cursos de Graduação em Enfermagem, Medicina e Nutrição. Brasília (DF): ME; 2001. 